\title{
Depression Among Undergraduate Medical Students
}

\author{
Basnet B, Jaiswal M, Adhikari B, Shyangwa PM
}

Department of Psychiatry

B.P.Koirala Institute of Health Sciences.

Dharan, Nepal

Corresponding Author

Bibhusan Basnet

B.P.Koirala Institute of Health Sciences.

Dharan, Nepal

E-mail: bibhusan117@hotmail.com

\section{Citation}

Basnet B, Jaiswal M, Adhikari B, Shyangwa PM. Depression Among Undergraduate Medical Students. Kathmandu Univ med J 2012;39(3):56-59.

\section{ABSTRACT \\ Background}

Psychological stress is common in medical school and associated with depression. Medical education is grooming in Nepal, but only few studies are done concerning mental health of medical students.

\section{Objective}

To assess the prevalence of depression among medical students at different levels of education and find about their stressors.

\section{Methods}

A cross sectional, questionnaire-based survey was carried out among the undergraduate medical students of B.P.Koirala Institute of Health Sciences, Nepal. 50 students each from Bachelor of Medicine and Bachelor of Surgery (MBBS) first and third year were enrolled in the study conducted between November 2008 to January2009. The depression levels were assessed using Zung depression scale. Students were asked to complete the questionnaire and then the depression levels calculated .The stress inducing factors during their course of medical education were also assessed.

\section{Results}

The overall prevalence of depression among the students was 29.78 percent. The prevalence of depression in first and third year was 36.74and 22.22 percent respectively. The prevalence of depression was 32.43 percent among female students versus 28.07 percent in male students. Both first and third year students gave high ratings to academic stress and hectic lifestyle as the main stress inducing factors.

\section{Conclusion}

The prevalence of depression is seen especially in the first year medical students. So, attempts should be made to alleviate the stressors right from the time they join medical school. Since academic stress proved to be one of the major factors, measures to make the academic curriculum more student-friendly are suggested.

\section{KEY WORDS}

Depression, medical students, zung depression scale

\section{INTRODUCTION}

Medical students are known to be the victims of tremendous mental stress. ${ }^{1}$ Yet it's often hard for all to see the sad faces behind the white coats. Medical students encounter multiple psychological changes in transformation from young insecure students to an efficient physician. The personal and social sacrifice they have to make in order to maintain a good academic result in a highly competitive environment puts them under a lot of stress. ${ }^{2}$ Previous studies have shown fairly high levels of distress, such as symptoms of depression among medical undergraduates. . $^{3,4}$ In recent years, depression has been recognized as a major morbidity in medical schools and the various factors that have been seriously affecting their academic performance and quality of life has been appreciated. ${ }^{5}$ However, only few studies are done in medical schools of Nepal. It is important for medical educators to know the magnitude of depression in students and factors causing them, which not only affect their health and academic achievement but also has serious consequences as suicide. ${ }^{6,7}$

Thus, we carried out a 20 questionnaire based cross sectional study to find out the prevalence of depression in medical school. This study was carried out with the following objectives. 
To assess the prevalence of depression among medical students at different levels of education taking gender differences into account.

To find about the possible stress inducing factors.

\section{METHODS}

The Study was a descriptive cross sectional study conducted at B.P. Koirala Institute of Health Sciences, Dharan, Nepal during the period of November 2008 to January 2009. Hundred students, 50 each from Bachelor of Medicine and Bachelor of Surgery (MBBS) first and third year were included in the study after randomized sampling on the basis of roll numbers from the total students (including the repeaters). The recruited students were informed about the purpose of study and explained about the general instructions.Informed consent was taken prior to the study. The students were allowed to respond in their own time and privacy. The participation was entirely voluntary. The study was approved by the Research Ethical Committee, BPKIHS. Then they were given the questionnaires which comprised of personal data, Zung Depression Inventory \& stress inducing factors.

- Personal Data: This included age, sex, batch, religion and home country.

- Zung Depression Scale: It is a 20 itemed self rated questionnaire which assess the level of depression symptoms. ${ }^{8}$ It has already been used in primary care and community settings and as a screen for depression. ${ }^{9}$ This Zung depression inventory is observed to have satisfactory psychometric properties with Cronbach's alpha of $0.79 .^{10}$ It contains 10 positive questions for e.g. "I eat as much as I used to" and 10 negative questions for e.g. "I notice that I am losing weight". Answers thus obtained are scored between one to four for each question with a total score ranging from 20 to 80 . A score less than 50 were considered to represent a case with no depression while a score $\geq 50$ was considered to represent a case with depression.

- $\quad$ Stress inducing factors: After in-depth literature review and peer consultation, five most important stress inducing factors were selected. The students were asked to strike the factors they thought to be important from the following. ${ }^{11}$
a) Academic stress
b) Home sickness
c) Relationships
d) Hectic lifestyle
e) Future concerns

Data were entered into Microsoft excel and analyzed using SPSS 12.0 statistical software. Prevalenceof an outcome variable along with 95 percent confidence interval was calculated. The parametric data was analyzed using mean, standard deviation and percentages while the nonparametric data was analyzed using chi square tests.

\section{RESULTS}

Out of the 100 questionnaires distributed to the medical students, 94 were returned completed, giving a response rate of $94 \%$.

Out of the 94 respondents, 57 were males and 37 females. Fourty nine students were enrolled in First year of study and 45 students were from third year of medical school. The mean age of study subjects was 21.18 years with a standard deviation of 1.65 years and a range of 18 to 26 years. Majority of the students were Nepalese (73) followed by Indians (21) in nationality.

It was noteworthy that the overall prevalence of depression in medical students was found to be $29.78 \%$.

The prevalence of depression in first and third year of medical schooling is shown in table 1 . Interestingly, it was found to be more among the first year students than the third year students. The incidence of depression was found to be more among ( $p$ value: 0.12 ) female students versus male students though not statistically significant (0.62) which is shown in table 2.

Table 1. Prevalence of depression: First year versus Third year.

\begin{tabular}{|ccc|}
\hline $\mathbf{N}=\mathbf{2 8}$ & No. of depressed students & Percentage (\%) \\
\hline year 1 & 18 & 36.74 \\
\hline Year 3 & 10 & 22.22 \\
\hline
\end{tabular}

Table 2. Prevalence of depression: male versus female students.

\begin{tabular}{|lcc|}
\hline & $\begin{array}{l}\text { No. of depressed } \\
\text { students }\end{array}$ & Percentage (\%) \\
\hline Depressed females & 12 & 32.43 \\
\hline Depressed males & 12 & 28.07 \\
\hline
\end{tabular}

Table 3. Stress inducing factors versus year of study.

\begin{tabular}{|lllc|}
\hline FACTOR & Year 1 & Year 3 & P value \\
\hline Home sickness & $14(28.56 \%)$ & $11(22.22 \%)$ & .651 \\
\hline Future concerns & $8(16.32 \%)$ & $21(46.67 \%)$ & .001 \\
\hline Relationships & $20(40.82 \%)$ & $13(28.89 \%)$ & .226 \\
\hline Academic stress & $36(73.46 \%)$ & $38(84.44 \%)$ & .194 \\
\hline Hectic lifestyle & $22(44.89 \%)$ & $26(57.78 \%)$ & .212 \\
\hline
\end{tabular}

The ratings given by first and third year students to various stressors are shown in table 3. Academic stress, hectic lifestyle and relationships were mainly highlighted by first year students. Even students of third year emphasized on academic stress and hectic lifestyle. Future concerns were also found to be a significant stressor in third year students than in comparison to first year students.

\section{DISCUSSION}

The response rate of $94 \%$ renders an adequate sample of 
the population studied to fulfil the objectives of the study. The findings show the prevalence of depression (29.78\%) in our undergraduate medical students. This finding is comparable with the results of similar study done in Britain (31.2\%) but more in comparison to findings of studies from Sweden (12.9\%) and Manipal, Nepal(20\%). ${ }^{3,5,1} 2$ But in a study done in Pakistan, the prevalence of depression accounts to 60 percent, which is higher than the findings of our study. ${ }^{13}$ This increased levels of stress and consequently depression indicates a decrease of psychological health in our students which may impair students' behaviour, diminish learning and ultimately affect patient care. ${ }^{14}$

In our study, the prevalence of depression was found to be more in the first year medical students than the third year medical students. This finding could be due to students' just entering medical school after high school. Also, it is seen that as the years of training in a medical school increases, the prevalence of depression decreases which is also shown by similar studies that have reported prevalence of depression to be found less in the clinical years than the non-clinical years. ${ }^{5,14-16}$.This clarifies the need for early prevention and intervention of depression that is seen to be more in the first year of medical schooling itself.

Another finding of our study is that a gender difference regarding the association with depression was noted where female students reported a marginally higher prevalence of depression than in men .But this association was not found to be statistically significant $(p=0.651)$. A study done in a Pakistani medical school also showed that female students reported more depressive symptoms than their male counterparts. Other similar studiesalso report depression to be more in female students. ${ }^{16-18}$ This gender variation in depressive status in medical students could be the reflection of usual trend of high prevalence of depression in females as in the general population. ${ }^{19}$

Both the first year and third year students reported academic stress and hectic life style as their principal stress inducing factors. Even studies from Pakistan and India reported academic stress and exams as the most troublesome stressors. ${ }^{15,16}$ But in a study done in Britain, students did not report of overload as their major source of stress. ${ }^{12}$ This may reflect cultural differences or may have been because of the wording of open ended questions used in their study or difference in working environment. ${ }^{12}$

Future concerns were found to be a statistically significant stressor in third year medical students. Moreover, as the

\section{REFERENCES}

1. Mannapur B, Dorle AS, Hiremath LD, Ghattargi CH, Ramadurg U, Kulkarni KR. A study of psychological stress in undergraduate medical students at S.N Medical College, Bagalkot, Karnataka. Journal of Clinical and Diagnostic Research 2010;4(4):2869-74.

2. Wolf TM, Kissling GE. Changes in life-style characteristics, health and mood of freshmen medical students. J Med Edu 1984;59:806-14. third year medical students have clinical rotations in wards, they understand how they are destined to work as doctors in wards and OPD's and treating patients i.e. they see the challenges ahead and they begin to think for the post graduate entrance exams they have to face in future, so future concerns might have been shown to be a significant stressor in clinical years of medical schooling in our study.

There were several limitations to the study. Our study only included first and third year students in the sample.Also, only the well-studied principal stressors were assessed. The students were not questioned about their coping strategies and possible measures like, student counsellors, to alleviate the situation. However, the study has been able to throw some light about the mental health of medical students and their stress inducing factors. Medical schools in the United States and Canada have started health promotion programmes and have reported positive results in reducing the negative effects of stress upon medical student's health and academic performance. ${ }^{20,21}$ Others methods suggested for reducing stress are use of small groups for teaching and support, provision of recreation and sports and more participation in social activities. Even, Leisure activities can reduce stress in medical schools. ${ }^{16}$ Studies done in the US regarding the residents' working hours and the stress and the work performance is quite significant and has helped change policies. ${ }^{22}$

\section{CONCLUSION}

The results revealed a clear picture of the prevalence of depression in medical students which is especially in the first year medical students and marginally more in females. They should be supported by student counselling units in the first year of schooling itself as they may be able to cope up with stress in the later years. By identifying the symptoms of depression and the stress inducing factors at an early stage hopefully the psychological morbidity among medical students can be prevented and the ones in morbid state can be helped to seek the professional.

\section{ACKNOWLEDGEMENT}

The authors would like to thank the medical students of batch 2006 and batch 2008, BPKIHS, Dharan for their participation in the study. Also special thanks to Mr.Dharanidhar Baral, Associate professor, BPKIHS for his valuable analysis and advice on statistics and verifying the whole manuscript.

3. Dahlin $\mathrm{M}$, Joneberg $\mathrm{N}$, RunesonB. Stress and depression among medical students: a cross sectional study. Med Educ 2005;39(6):594604.

4. Sherina MS, Rampal L, KenesonN. Psychological stress among undergraduate medical students. Med J of Malaysia 2004;59(2):20711. 
5. Sreeramareddy CT,Shanker PR, Binu VS, Mukhopadhyay C, Ray B, Menezes RG. Psychological morbidity, sources of stress and coping strategies among undergraduate medical students of Nepal. BMC Med Edu 2007;7:26.

6. Tyssen R, Hem E, Vaglum P, Gronvold NT, Ekeberg O. The process ofsuicidal planning among medical doctors: predictors in a longitudinal Norwegian sample. J Affect Disord 2004;80(2-3):191-8.

7. Dyrbye LN, Thomas MR, Massie FS, Power DV, Eacker A, Harper W, et al. Burnout and suicidal ideation among U.S. medical students. Ann Intern Med 2008;149(5):334-41.

8. Zung WWK. A self-rating depression scale. Arch Gen Psy 1965;12:6370.

9. Meakin C. Screening for depression in the medically ill. $B r$ J Psy 1992;160:212-6.

10. Knight RG, Waal-Manning J, Spears GF. Some norms and reliability data for the State-Trait Anxiety Inventory and the Zung Self-Rating Depression Scale. Br J Clin Psychol 1983;22(4):245-9.

11. Vaidya PM, Mulgaonkar KP. Prevalence of depression, anxiety and stress in undergraduate medical students and its correlation with their academic performance. Indian J occup ther 2007;39(1):7-10.

12. Firth J. Levels and sources of stress in medical students. BMJ 1986; 292(6529):1177-80.

13. Inam SN, Saqib A, Alam E. Prevalence of anxiety and depression among medical students of private university. Pak Med Asso 2003;53(2):44-7.
14. Abdulghani HM. Stress and depression among medical students: a cross sectional study at a medical college in Saudi Arabia. Pak J Med Sci 2008;24(1):12-7.

15. Guthrie E, Black D, Bagalkote H, Shaw C, Campbell M, Creed F. Psychological stress and burnout in medical students: a five -year prospective longitudinal study. Jr Soc Med 1998;91(5):237-43.

16. 16.Shaikh B, Kahloon A, Kazmi M, Khalid H, Nawaz K,Khan N, et al. Students, stress and coping strategies: a case of Pakistani medical school. Educ Health 2004;17(3):346-53.

17. Lloyd C, Gartrell NK. Sex differences in student mental health. Am J Psy 1981;138(10):1346-51.

18. Davidson V. Coping styles of women medical students. Med Ed 1978; 53(11):902-7.

19. Sadock BJ , Kaplan HL ,Sadock VA. Kaplan and Sadock's Synopsis of Psychiatry. 8th ed. Philadelphia: Lippincott Williams \&Wilkins; 1998. p525.

20. Lee J, Graham A. Students' perception of medical stress and their evaluation of a wellness elective. Med Ed 2001;35(7):658-9.

21. Wolf TM, Randall HM, Faucett JM.A survey of health promotion programs in U.S and Canadian Medical Schools. Am J Health Promot 1988; 3(1):33-6.

22. S R Moonesinghe, J Lowery, N Shahi, A Millen, J D Beard. Impact of reduction in working hours for doctors in training on postgraduate medical education and patients' outcomes: systematic review. BMJ 2011;342: d1580. 